chronotype), yielding $\mathrm{CD}_{\mathrm{BN}}$ hours. Total CDhours may be obtained by summing up $\mathrm{CD}_{\mathrm{BN}}$ hours due to activities at and off work. As a more easily applicable metric, how much sleep overlaps with the individual biological day (BD) may yield $\mathrm{CD}_{\mathrm{BD}}$ hours.

Conclusions Epistemologically, shiftwork epidemiology is lacking chronobiological and methodological rigour. CD - like smoking - must be assessed at and off work to consider cumulative doses in studies of carcinogenicity. Epidemiological research before and after IARC 2007, based on (night)shifts alone, may have delayed or disallowed detection/measurement of the existence/magnitude of possibly carcinogenic effects of cumulative CD.

\section{Oral Presentation}

\section{Cardiovascular Disease}

\section{MORTALITY AMONG NORWEGIAN SMELTER INDUSTRY WORKERS - A 55 YEAR FOLLOW-UP}

Merete D Bugge*, Bente Ulvestad, Balazs Berlinger, Dag G Ellingsen. STAMI, National Institute of Occupational Health, Oslo, Norway

10.1136/oemed-2017-104636.255

Ambient air pollution is associated with increased incidence and mortality of cardiovascular disease. Time-series studies have shown that a $10 \mu \mathrm{g} / \mathrm{m} 3$ increase in mean 24 hour PM2 concentration increases the relative risk for daily cardiovascular mortality by $0.4 \%$ to $1.0 \%$. In recent years, increasing concerns have been levelled at the ultrafine component of PM. Ultrafine particles are formed during combustion of materials, and are therefore abundant in the furnace area of metal smelter plants.

In connexion with an ongoing project concerning occupational exposure to fine and ultrafine particles and risk of cardiovascular disease, an update of two large smelter worker cohorts has been performed. Mortality data were received from the Norwegian Causes of Death register for the period 1960-2014. The combined cohort consisted of 19660 men, with nearly 650000 person-years of follow-up. Preliminary analyses showed that both total mortality (SMR 1.09, 95\% CI 1.07-1.11) and mortality from all cardiovascular diseases (SMR 1.03, 95\% CI 1.00-1.06) were significantly increased compared to the Norwegian general male population. Workers with employment in furnace work had total mortality SMR 1.18 (95\% CI 1.15-1.21) and cardiovascular mortality SMR 1.09 (95\% CI 1.04-1.14). Smelter workers with no furnace work had total mortality SMR 1.01 (95\% CI 0.99-1.04) and cardiovascular SMR 0.99 (95\% CI 0.95-1.02). The further data analyses are currently in progress.

\section{Oral Presentation}

\section{Musculoskeletal}

\section{EFFECT OF MULTISITE MUSCULOSKELETAL PAIN ON HEALTH RELATED JOB LOSS: FINDINGS FROM THE HEALTH AND EMPLOYMENT AFTER FIFTY (HEAF) STUDY}

Georgia Ntani*, Stefania D'Angelo, Clare Harris, Karen Walker-Bone, David Coggon Keith Palmer. MRC Lifecourse Epidemiology Unit, University of Southampton, Southampton, UK

\subsection{6/oemed-2017-104636.256}

Background Musculoskeletal pain (MSP) at multiple anatomical sites differs from single site pain both in its risk factors and prognosis. Multisite MSP is more likely to cause sickness absence from work, but knowledge about its effect on healthrelated job loss (HRJL) is limited. To explore this association we analysed longitudinal data from participants aged 50-64 recruited to the Health and Employment After Fifty (HEAF) study.

Method Baseline information collected by postal questionnaire from 4333 employed participants included questions about MSP in the past year at three anatomical sites (spine, upper, and lower limb). Subsequent HRJL was ascertained through a follow-up questionnaire after one year. Associations between multisite MSP (pain at $\geq 2$ anatomical sites) and HRJL were explored using Poisson regression with robust variance and summarised by prevalence rate ratios (PRRs).

Results Among 437 participants with multisite MSP at baseline, $7 \%$ left their job due to ill health, compared to $3 \%$ in 547 with single-site pain and 2\% in 3349 without MSP. After accounting for potential confounders, the risk of HRJL was higher among those with multisite MSP than in those with single-site MSP (fully-adjusted PRRs 1.9 (95\%CI 1.1-3.2) and 1.6 (95\%CI 0.9-2.7) compared with no MSP). The population attributable fraction for single-site pain was 7\%, while that of multi-site pain was $15 \%$.

Conclusions This analysis suggests that multisite MSP carries a higher risk of HRJL than single-site pain. To develop future preventive strategies, efforts should focus on understanding the drivers of multisite MSP rather than concentrating on sitespecific risk factors.

\section{Poster Presentation}

\section{Injuries}

\section{OBSTRUCTIVE SLEEP APNEA SYNDROME (OSAS) IN ROAD TRAFFIC ACCIDENTS OF COMMERCIAL BUS AND TRUCK DRIVERS IN CENTRAL IRAN}

\footnotetext{
1,2Mehrzad Ebrahemzadih*, ${ }^{2}$ Gholam Hossein Halvani. 'Environmental Health Research Centre, Kurdistan University of Medical Sciences, Sanandaj, Iran; ${ }^{2}$ Department of Occupational Health, Shahid Sadoughi University of Medical Sciences, Yazd, Iran
}

10.1136/oemed-2017-104636.257 